SMAD, Rev. Eletrônica Saúde Mental Álcool Drog.

2020 maio-jun.;16(3):1-2

DOI: 10.11606/issn.1806-6976.smad.2020.000091

www.revistas.usp.br/smad/

\title{
Mindfullness pode modular nossa imunidade?
}

\author{
Evelin Capellari Cárnio ${ }^{1}$ \\ (D) https://orcid.org/0000-0002-8735-4252
}

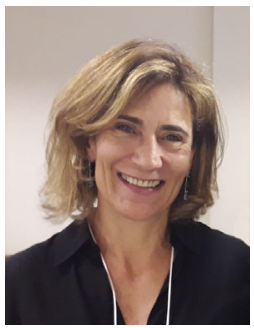

Mindfulness, a atividade que se realiza através da prática da conscientização e aceitação sem julgamento da experiência vivida momento a momento, é considerada um antídoto potencialmente eficaz contra formas comuns de sofrimento psíquico, ansiedade, preocupação, medo, raiva, etc.

Recentemente, a ideia de que tais estados mentais podem participar também da regulação homeostática de nosso corpo vem sendo muito discutida. De acordo com estudos de pesquisadores do Massachusetts General Hospital, em Boston, e da University of Massachusetts Medical School, em Worcester, que avaliaram imagens cerebrais de pessoas que realizam o mindfulness rotineiramente, essas apresentam diferenças estruturais quando comparadas com a de indivíduos que não o realizam. Os efeitos neuroestruturais do mindfulness foram detectados no cérebro, observando-se alterações estruturais tanto na substância cinzenta como na branca, particularmente em áreas relacionadas à atenção, memória, interocepção e processamento sensorial ou de auto-regulação (incluindo controle do estresse e emoções) ${ }^{(1)}$. Alterações neurofuncionais também foram citadas, como a diminuição da atividade do cortisol e da noradrenalina, neurotransmissores ligados à situação de estresse, e também elevando a atividade da dopamina, melatonina e serotonina, substâncias que estão relacionadas com a indução do sono e a sensação de bem estar e felicidade.

Em estudo realizado em nosso grupo, demonstramos, em modelo animal submetido à situação de inflamação sistêmica, que a administração central de serotonina foi capaz de atenuar a ativação do reflexo inflamatório, diminuindo a resposta de inflamação(2). Nesse sentido, nos questionamos se poderíamos extrapolar que a prática do mindfulness, que de alguma forma estimula a produção de serotonina em áreas do sistema nervoso central, poderia favorecer a nossa resposta do sistema imunológico.

\footnotetext{
1 Universidade de São Paulo, Escola de Enfermagem de Ribeirão Preto, Centro Colaborador da OPAS/OMS para o Desenvolvimento da Pesquisa em Enfermagem, Ribeirão Preto, SP, Brasil.
}

\section{Como citar este artigo}

Cárnio EC. Can Mindfulness modulate our immunity? SMAD, Rev Eletrônica Saúde Mental Álcool Drog. 2020;16(3):1-2. doi: https://dx.doi.org/10.11606/issn.1806-6976.smad.2020.000091. 
Acredito no crescimento dessa área de conhecimento e que novos estudos em breve trarão grandes avanços, respondendo questões onde as funções cerebrais e de outras áreas fisiológicas e fisiopatológicas poderiam ser integradas.

\section{Referências}

1. Hölzel BK, Carmody J, Evans KC, Hoge EA, Roger K, Dusek JA, et al. Stress reduction correlates with structural changes in the amygdala. Soc Cogn Affect Neurosci. 2010 Mar; 5(1): 11-7. doi: https://doi.org/10.1093/scan/ nsp034

2. Mota CMD, Borges GS, Amorim MR, Carolino ROG, Batalhão ME, Anselmo-Franci JA, et al. Central serotonin prevents hypotension and hypothermia and reduces plasma and spleen cytokine levels during systemic inflammation. Brain Behav Immun. 2019 Aug;80:255-65. doi: 10.1016/j.bbi.2019.03.017

Copyright $\odot 2020$ SMAD, Rev. Eletrônica Saúde Mental Álcool Drog. Este é um artigo de acesso aberto distribuído sob os termos da Licença Creative Commons CC BY.

Esta licença permite que outros distribuam, remixem, adaptem e criem a partir do seu trabalho, mesmo para fins comerciais, desde que the atribuam o devido crédito pela criação original. É a licença mais flexível de todas as licenças disponíveis. É recomendada para maximizar a disseminação e uso dos materiais licenciados. 